\title{
Introduction to the Special Issue
}

\section{Vocational Rehabilitation Issues and Outcomes for People with Chronic Illnesses}

\author{
Phillip D. Rumrill Jr ${ }^{\mathrm{a}, *}$ and Malachy Bishop ${ }^{\mathrm{b}}$ \\ ${ }^{a}$ Kent State University, Kent, OH, USA \\ ${ }^{\mathrm{b}}$ University of Kentucky, Lexington, KY, USA
}

Revised/Accepted January 2015

David is a 46 year-old man who works as a Certified Financial Planner with a large investment firm in the Southwestern United States. He works with clients in person, over the telephone, and online to help them establish long-term financial objectives; save for college tuition and retirement; manage household debt; purchase stocks, bonds, and mutual funds; and prepare their estates for succeeding generations of family members. David works full-time, up to 60 hours per week, on a 12month basis. His job requires frequent automobile travel to meetings and conferences in the community and airplane travel to conferences once or twice per year.

David was diagnosed with Type II diabetes mellitus at the age of 37 . He regulates his blood sugar through diet, regular exercise, and orally-ingested insulin pills. Symptoms of David's diabetes include fatigue, numbness in his hands and feet due to circulatory problems, occasional blurred vision, excessive bruising, and memory deficits when he experiences fatigue. David takes accrued sick leave when he is unable to work, and he uses a hand-held electronic planner to combat his problems with memory. In fact, he has taken to using the hand-held device at all times. David will also ask his employer to make minor scheduling modifications on days when he is working and experiencing fatigue. One such scheduling modification involves David holding his client meetings in the morning and early afternoon

\footnotetext{
*Address for correspondence: Phillip D. Rumrill Jr., Kent State University, 413 White Hall, PO Box 5190, Kent, OH 44242-0001, USA. Tel.: +1 330672 0600; Fax: +1 330672 2512; E-mail: prumrill@kent.edu.
}

so he can go home early and rest. Because all of the Certified Financial Planners in David's firm schedule their own client meetings, this is an easy and no-cost accommodation for David to implement.

David has disclosed his diabetes to his employer, and the scheduling modification and the hand-held planner are the only accommodations he requires to do his job at this time. Several of David's friends at work know about his diabetes. David is doing well in his job and managing his symptoms fairly effectively, but he sometimes worries about the future and whether his health will decline.

Thanks in large measure to advances in medical technology and treatment, millions of people like David are living longer and more comfortably while they cope with chronic illnesses. This is certainly an encouraging trend, but, at the same time, it has created unique challenges for the systems that provide services for people with disabilities. As growing numbers of children with chronic diseases graduate from public schools and enter adulthood, vocational rehabilitation professionals will be called upon more frequently to assist them in their pursuit of independent life roles. On the other end of the career continuum, people are putting off retirement until later in life than ever before, a phenomenon that has substantially increased the number of American workers who develop age-related illnesses (e.g., diabetes, arthritis, cancer, heart disease).

As these patterns continue, they converge to pose major implications for the vocational rehabilitation (VR) process. On one hand, career guidance, train- 
ing, and placement assistance will continue to be in heavy demand from youth with chronic illnesses seeking to make the transition to competitive careers. On the other, post-employment services such as selfadvocacy training, consultation with employers, and planning for reasonable accommodations will be more actively sought by members of the ever-aging workforce who acquire mid-career illnesses. Hence, it is more important than ever for rehabilitation professionals to acquaint themselves with the often debilitating effects of chronic illnesses - effects that go far beyond the medical symptoms of each disease.

Specifically, the psychological uncertainty that accompanies an unpredictable, sometimes progressive illness makes it difficult for the person to participate in the planful, outcome-based VR process. Unlike static conditions such as traumatic spinal cord injuries or congenital blindness, chronic illnesses bring with them a non-linear, fluctuating adjustment cycle that often leaves the person waiting for his or her next relapse rather than developing pro-active coping strategies.

Fortunately, the Americans with Disabilities Act Amendments Act (ADAAA), which took effect on January 1, 2009, has expanded the definition of disability to include David and many more Americans who are coping with chronic illnesses. In fact, people with multiple sclerosis, cancer, diabetes, epilepsy, muscular dystrophy, and HIV/AIDS are now presumptively considered people with disabilities under the law. This status entitles them to the full measure of the civil rights protections in Employment, Public Services, Public Accommodations, and Communications that are set forth in the ADAAA.
To effectively serve people with chronic illnesses in their efforts to work and participate fully in all aspects of society, rehabilitation professionals must (1) become familiar with the medical aspects of commonly reported diseases, (2) understand the psychological tolls that chronic illness exacts on the person and his or her significant others, (3) gauge the extent to which medical and psychological factors conjoin to impede the person's prospects for successful employment, and (4) develop knowledge of resources and model programs that can assist people with chronic illness in establishing and/or maintaining their careers. With that in mind, the purpose of this special issue is to provide current information for practitioners, researchers, administrators, disability advocates, and employers as the VR process is called upon to serve more people with chronic illnesses. One article in this issue treats the concept of chronic illness in general terms, whereas others focus on the vocational and community living implications of specific illnesses such as multiple sclerosis, arthritis, cancer, and diabetes mellitus. Readers will also note a wide range of research designs and data analytic methods in the empirical articles presented in this issue. This diversity of subject matter and methodology was sought in consideration of JVR's diverse, interdisciplinary readership.

We would like to thank our fellow researchers and authors who contributed articles to this issue. We sincerely appreciate their willingness to share their expertise with JVR's readers in this forum. Special thanks go to Dr. Paul Wehman, Editor of JVR, for commissioning this edition. 